Received: November 29, 2017

Revision received: March 22, 2018

\title{
Analysis of Current Situation and Optimization Plan for Sensor Course Teaching*
}

\author{
Juan Tang ${ }^{1}$ \\ Hebei Agricultural University \\ Wendi Wang ${ }^{3}$ \\ Hebei Agricultural University
}

\author{
Lihua $\mathrm{Li}^{2}$ \\ Hebei Agricultural University \\ Limin Shao ${ }^{4}$ \\ Hebei Agricultural University
}

\begin{abstract}
In view of the fact that there are problems of too few practical contents and too slow knowledge absorption in the course of "sensor principle and application" in colleges and universities, this paper analyzes the content of sensor course. Based on the study habits of students in this major, it proposes revision suggestions to the core links of the teaching of this course. This program teaches students in accordance of their major, and raises the weight of the experimental courses. This method can effectively improve students' interest in learning, enhance their subjective initiative, and further develop their innovation ability and practical ability.
\end{abstract}

\section{Keywords}

Sensor Course • Experimental Teaching • Autonomous Learning • Innovation Ability

\footnotetext{
* The tenth batch of teaching research projects of Hebei Agricultural University (Grant: 2018YB27).

${ }^{1}$ Juan Tang, College of Mechanical and Electrical Engineering, Hebei Agricultural University, Baoding, China; Key Laboratory of Broiler Chicken Breeding Facilities, Ministry of Agriculture, Baoding, China. Email: slimmyshao@ hotmail.com ${ }^{2}$ Lihua Li, College of Mechanical and Electrical Engineering, Hebei Agricultural University, Baoding, China; Key Laboratory of Broiler Chicken Breeding Facilities, Ministry of Agriculture, Baoding, China. Email: 1lh@ hebau.edu.cn ${ }^{3}$ Wendi Wang, College of Mechanical and Electrical Engineering, Hebei Agricultural University, Baoding, China; Email: 112574407@qq.com

${ }^{4}$ Correspondence to: Limin Shao (MSc), College of Mechanical and Electrical Engineering, Hebei Agricultural University, Baoding, China; Email: shaolimin@ hebau.edu.cn
} 
Sensor is one of the basic courses of modern information technology. It has a wide application in civil and in military, and it's a very practical course. With the continuous development of computer technology, Internet of Things and automation control technology, the demand for sensor professionals is increasing rapidly, so colleges and universities are paying more and more attention to this course (Zhang, Jing, Gui \& Zhang, 2008). In the context of rapid updating of integrated circuits and microelectronics, modern sensors are becoming lighter and faster, their performance has improved rapidly, and now they can meet the requirements of miniaturization, intelligence and networking in many fields. As an important related discipline in the fields of Internet of Things, artificial intelligence, virtual reality, etc., sensors and the related information technology and industry have been included in the special science and technology projects of the national "Eleventh Five-Year Plan" (Inman, Loge $\&$ Leavens, 1997). The industry scale of China's sensor industry is as follows:

Figure 1

\begin{tabular}{ccc}
\multicolumn{4}{l}{ Sensor Market Scale } \\
\hline Year & Scale (billion) & Increase rate \\
\hline 2014 & 105.5 & $23 \%$ \\
2015 & 126.0 & $20 \%$ \\
2016 & 153.7 & $25 \%$ \\
2017 & 174.1 & $10 \%$ \\
2018 & 190.0 & $9.5 \%$ \\
\hline
\end{tabular}

\section{Current situation of sensor course teaching}

For many years, sensor courses were mainly concentrated in the fields of electronic information, computer application, automation and other science and engineering majors. In recent years, with the improvement of the performance of sensors, the application field has been expanding, and bioengineering, aerospace and other majors have begun to set up this course as well (Stroble, Watkins \& Stone, 2009; Sorrente, Michau, Fleury, Conan, \& Sauvage, 2017; Khalifeh, Lescop, Gallée, Le Roux, \& Rioual, 2016). In recent years, the statistics of sensor courses in China's major higher-education provinces are as follows:

Figure 2

\begin{tabular}{lccc}
\multicolumn{4}{l}{ Sensor Course Statistics } \\
\hline Province & Graduate university & College & junior college \\
\hline Guangdong & 38 & 77 & 90 \\
Jiangsu & 25 & 64 & 87 \\
Shandong & 24 & 67 & 78 \\
Henan & 35 & 55 & 79 \\
Hebei & 38 & 68 & 61 \\
Hunan & 27 & 51 & 60 \\
Anhui & 24 & 61 & 62 \\
Sichuan & 26 & 45 & 74 \\
Zhejiang & 35 & 64 & 47 \\
Jiangxi & 26 & 59 & 58 \\
Beijing & 39 & 53 & 63 \\
Shanghai & 34 & 59 & 72 \\
Tianjin & 25 & 46 & 51 \\
Chongqing & 15 & 32 & 33 \\
\hline
\end{tabular}

From the feedback of the campus recruitment market and the actual teaching results, the cultivation of sensor technology professionals in domestic universities can basically meet the needs of the employment market. 
However, in recent years, as the market's demand on the graduates' practical ability and innovation ability is increasing continuously, and the quality of students is declining due to university enrollment expand, companies have begun to reflect that the engineering ability of graduates is declining, and the training cycle and costs of enterprises have risen. The students' creativity is relatively weak, and the new products they designed can hardly meet the demands of the market. After investigation and analysis, this paper believes that the current sensor teaching in colleges and universities mainly has the following problems.

\section{Teaching content is outdated}

The teaching content of sensor curriculum was first introduced in the 1990s. The main content of sensor course is based on the theory of signal processing and semiconductor physics. In recent years, with the development of new technologies, sensors in different fields have been widely developed, and even sensor protocols are increasing. Therefore, it requires the sensor teaching content to be able to quickly respond to changes in the needs of different professions. At the same time, the selection of sensors should also have a professional focus. At present, in our course teaching scheme, the characteristics of the subdivision profession are not well reflected, for example, such as electronic communication, automation control, and aerospace professions have different working contents for the sensors. At the same time, the types of sensors used in the work are also quite different. Nowadays, according to the subdivision professions, teaching is conducted differently in the higher education teaching system. Most colleges and universities use the same textbooks and the same syllabus. It is true that this way can improve teaching efficiency, so that college teachers can pay more attention on the preparation of basic textbooks, but this method of unifying textbooks obviously constrains the needs of subdivided professions, leading to "thousand a voice" in the mastering of the knowledge of sensors, which increases the training cost of employers.

\section{Teaching method is outdated}

The sensor course is characterized by fragmentary knowledge, scattered content and high practicality, and it has high requirements on physics, mathematics, and other basic knowledges (Yedavalli \& Krishnamachari, 2007). At the same time, it's not systematic and lacks continuity, in the learning process, students can hardly understand this course, while the classroom time in universities and colleges is quite limited, teachers have to explain a lot of complex sensor knowledge within a very limited time, resulting in high costs for students to understand and digest this course (Lindsey \& Raghavendra, 2012). However, the traditional teaching mode of sensor course is still writing and drawing with blackboard and chalk, and obviously this mode can hardly meet the teaching requirements of this complex course (Islam, Mukhopadhyay, \& Suryadevara, 2017). Therefore, in the teaching process, we can't just focus on traditional method of "teachers speaking and students listening", otherwise the students are always in a passive state of learning, they are not really interest in the course, and the teaching efficiency is low.

\section{Practical ability and innovation ability are weak}

The sensor is a subject that takes practice as the goal, and good engineering practical ability is an important criterion for measuring the success of the course (Franceschini, Galetto, Maisano \& Mastrogiacomo, 2009). 
Due to the limitations of devices and teaching equipment, the current sensor teaching mainly takes the teaching of principle and verification as the core content, and it lacks systematic and practical experiments, resulting in students' inability to build sensor system using components by themselves, and they don't have engineering ability or the ability to solve practical problems. After graduation, students couldn't remember or understand the theoretical problems, and they can't quickly get the job done by their own hands. They just become a kind of inheriting and imitating professionals, far from the enterprises' requirement of "good hands-on ability and quick learner". The sensor experiment course is also based on the traditional experimental teaching method which is conducted according to the standards of each stage, and the main content of the experiments cannot keep up with the actual production needs of the enterprises. The experiments are mainly comprehensible experiments for formulas and theories, and there's no content that are related to the engineering production, resulting in that the experiments in this course are separating from the enterprises' practice, the correlation can't be guaranteed and the teaching is not systematic at all. So, it is difficult to reflect the interdisciplinary and widerange characteristics of the sensor course, which is not conducive to the cultivation of students' practical ability. The main root of these problems lies in the drawbacks of the teaching content and teaching mode of the sensor course. Changing the deficiencies in the original teaching mode, strengthening the practice links, and cultivating "high-quality applied talents with innovative consciousness and practical abilities" are a major challenge in front of colleges and universities, and an important direction for the teaching reform of sensor courses.

\section{Innovation practice is weak}

In the traditional experimental teaching, the task of students' experimental results is only carried out according to the course teaching and experimental verification. The experimental results and completion of experimental reports determine students' experimental scores. Usually the experimental results account for 20\%-30\% of the course scores. This kind of teaching method can't guide students to better understand the important principles of sensors through experiments. Students are always in a state of completing tasks passively, which would reduce students' enthusiasm for learning and is not conducive to the cultivation of students' innovative thinking.

\section{Improvement plan}

According to the above analysis, it can be seen that the sensor course teaching in colleges and universities has limited the students' innovative thinking to some extent due to the traditional teaching schemes and unreasonable curriculum settings. As a result, students have low interest in learning and it is difficult to exert their subjective initiative, they only take the sensor course as an examination task. Under this context, it is not conducive to the construction of disciplines and the cultivation of talents, and it is also difficult to deliver qualified talents for enterprises. Therefore, the improvement of sensor experiment teaching is very urgent. Based on the needs of the employment market in recent years, this paper proposes an improvement plan for the sensor technology experimental course to improve students' innovation ability, engineering ability and skills in subdivision professions. 


\section{Independent experimental teaching}

Separate the teaching of experimental content from the sensor teaching or give higher score weight to it, grant higher initiative to the experimental curriculum of sensor teaching so that it can get rid of the theoretical teaching, and we can use experimental teaching to improve students' hands-on practical ability. The teaching rhythm of the experimental course should mainly focus on cultivating comprehensive design abilities and meeting the enterprises' requirements of talents in its experimental orientation, it should be promoted with teaching content in curriculum as the main line, and the repeated experimental results should be strictly distinguished. We must forbid students from plagiarizing each other. From simple to complex, step by step, we need to integrate the teaching content of basic knowledge, change more experimental classes into practical lessons. Also, we need to start from the needs of enterprises and work, simulate actual product practice in the production process, and reduce excessive contents of traditional sensor experiment teaching in simple verification and basic experiments, so as to pave foundation for cultivating students' comprehensive ability, practical ability and innovation ability.

\section{Subdivided teaching content}

When the content of the teaching is decided, according to the characteristics of each major and the enterprises' actual requirements for talents, we should start from the goal of cultivating innovative engineering talents, layer by layer, establish the six major modulus of basic knowledge teaching, basic knowledge experiment, comprehensive knowledge teaching, comprehensive knowledge experiment, sub-domain knowledge teaching, and sub-domain experiment, so that the sensor teaching can step into a refined and professional route. The basic skill contents include basic electronic components and use of measuring instruments, which lay a solid foundation for follow-up teaching and experimentation; comprehensive knowledge and experiment refers to the basic theories in the sensor curriculum, it deepens the study of relevant knowledge through classroom teaching and experimental content, the experimental part can be completed either by experimental equipment or by using software such as matlab, simulink, and EDA (Ghazi \& Ahiod, 2017). The comprehensive knowledge aims to develop students' ability to comprehensively apply sensor theory knowledge to analyze and solve problems, including the content of the course itself and the integration between different courses. The internal contents of the course are: finish the self-inductive sensor design course and fabricate a gap-changeable inductive sensor; finish the piezoelectric sensor design course and fabricate a device that directly realizes force-to-electricity conversion by using force-sensitive components and transduction elements; realize a force sensor during circuit, even extend to diaphragm-type sensor, and strain force sensor, etc. Integration between different courses is: according to the content of the EDA course, adopt the EDA technology combined with single-chip microcomputer, matlab simulation and zigbee protocol (Blumenthal, Grossmann, Golatowski \& Timmermann, 2007) to complete a wireless routing sensor system. Sub-domain knowledge teaching and experiment aims to teach students of different majors about the knowledge of sensors that are related to their majors, such as a student of electronic communication major can independently complete the circuit board design of the communication system through his/her study of sensor course combined with 
communication principles, digital circuits and other knowledge, and he/she can realize the proposed algorithm, demonstrate the plan, finish the design of circuit and software, and complete the circuit board soldering. The whole process debugging should be completed by scientific research teams formed by students. For the more difficult part, senior students or even the graduate students can be invited to join in the teams, and teachers need to provide necessary technical guidance and experimental direction; this teaching method cultivates scientific research methods for students and improves their problem-solving abilities, which can well meet the needs of enterprises and lay a good foundation for students to go out into the world in the future. Students who have spared ability can even take this as an opportunity to join in the instructor's laboratory for further research.

\section{Implementation of open experimental teaching}

Learn from excellent foreign universities of their advanced experience and build up open laboratories. In the laboratories, chronically offer teaching experimental kits such as breadboards, microcontroller development boards, and programmers, by IC cards or other methods we can control students' access to the laboratories and facilities. This automated method can provide convenience for students' practice, it allows students who are interested to choose their own experiment time and experiment site, and it opens up the experimental contents to let students choose experimental projects by themselves. This method fully enhances students' initiative, as a supplement and improvement to daily teaching method, it has been widely welcomed by students in practice. Students can reasonably arrange their own time, use experiments to verify, consolidate, and further understand the theoretical knowledge they have learned in the classroom. For topics interest them, they can verify them in the laboratories, or if they have a new idea, they can also build up prototype in the laboratories. In addition, in open laboratories, they can meet with senior students, by exchanging with senior students, it will contribute sparks of new thoughts and mobilize students' learning initiative and enthusiasm.

\section{Combination of multiple teaching modes}

Nowadays, college students are mainly the post-1990s and post-2000s generations, students of these generations are characterized by distinct personality and active thoughts. Therefore, more novel and deliberate teaching modes are needed to transmit teaching knowledge more effectively. We can integrate interest groups, online teaching, classroom discussion and other teaching methods with case studies to broaden students' knowledge and enable them to truly enter the world of sensors, in this way we can narrow the gap between theory and practice, and improve students' problem-solving abilities. For example, in recent years, smart home has become one of the most important scenes for the use of sensors. A large number of related products have emerged at home and abroad. We can use Internet, multimedia and other methods to present various successful cases of smart home at home and abroad to students, let them have an intuitive feeling of sensors and eliminate strangeness, so that theoretical knowledge can be integrated with practical application to make students easily master knowledge of sensors. In addition, teachers are encouraged to combine with their own research results to teach enterprise cases to students and inspire their innovative thinking. Under this condition, the more the teacher's scientific research results, the richer the teaching content. 


\section{Conclusion}

This paper analyzed in-depth the current situation and existing problems of the sensor course teaching mode. Based on enterprises' requirement for talents, it proposed shortcomings in the current teaching mode. Starting from the aspects of practical ability, innovation ability and problem-solving ability, it put forward reform program for sensor teaching, which can stimulate students' interest in learning, enhance their engineering ability and innovation ability, so as to achieve the purpose of improving teaching quality and cultivating outstanding talents.

\section{References}

Blumenthal, J., Grossmann, R., Golatowski, F., \& Timmermann, D. (2007). Weighted centroid localization in zigbee-based sensor networks. Proc. IEEE International Symposium on Intelligent Signal Processing, Wisp 2007, Alcala De Henares, Spanish, 1-6. http://dx.doi.org/10.1109/WISP.2007.4447528

Franceschini, F., Galetto, M., Maisano, D., \& Mastrogiacomo, L. (2009). A review of localization algorithms for distributed wireless sensor networks in manufacturing. International Journal of Computer Integrated Manufacturing, 22(7), 698-716. http://dx.doi.org/10.1080/09511920601182217

Ghazi, A. E., \& Ahiod, B. (2017). Energy efficient teaching-learning-based optimization for the discrete routing problem in wireless sensor networks. Applied Intelligence, (4), 1-15. http://dx.doi.org/10.1007/s10489-0171108-8

Inman, D. P., Loge, K., \& Leavens, J. (1997). Vr education and rehabilitation. Communications of the Acm, 40(S3), A14-A14. http://dx.doi.org/10.1109/ITAB.2008.4570554

Islam, T., Mukhopadhyay, S. C., \& Suryadevara, N. K. (2017). Smart sensors and internet of things: a postgraduate paper. IEEE Sensors Journal, 17(3), 577-584. http://dx.doi.org/10.1109/JSEN.2016.2630124

Khalifeh, R., Lescop, B., Gallée, F., Le Roux, G., \& Rioual, S. (2016). Development of a new method of corrosion monitoring by wireless sensors based on RFID technology, Instrumentation Mesure Metrologie, 15(3-4), 153-160. http://dx.doi.org/10.3166/I2M.15.3-4.153-160

Lindsey, S., \& Raghavendra, C. S. (2002). PEGASIS: Power-efficient gathering in sensor information systems. http://dx.doi.org/10.1109/AERO.2002.1035242

Sorrente, B., Michau, V., Fleury, B., Conan, J.M., \& Sauvage, J.F. (2017). Measurement of the index field with a pyramidal sensor, Instrumentation Mesure Metrologie, 16(1-4), 213-228. http://dx.doi.org/10.3166/I2M.16.1-4.213-228

Stroble, J. K., Watkins, S., \& Stone, R. (2009). Biology-inspired sensor design. IEEE Potentials, 28(6), 19-24. http://dx.doi.org/10.1109/MPOT.2009.934892

Yedavalli, K., \& Krishnamachari, B. (2007). Sequence-based localization in wireless sensor networks. IEEE Transactions on Mobile Computing, 7(1), 81-94. http://dx.doi.org/10.1109/TMC.2008.4387797

Zhang, W., Jing, S., Gui, L., \& Zhang, Y. (2008). Physiological data acquisition system for education assessment using wireless sensor network. International Conference on Information Technology and Applications in Biomedicine, 471-473. http://dx.doi.org/10.1109/ITAB.2008.4570554 